\title{
Fetal Abdominal Obesity Detected At 24 to 28 Weeks of Gestation Persists Until Delivery Despite Management of Gestational Diabetes Mellitus (Diabetes Metab J 2021;45:547-57)
}

\author{
Kyung-Soo Kim \\ Department of Internal Medicine, CHA Bundang Medical Center, CHA University School of Medicine, Seongnam, Korea
}

The global incidence of gestational diabetes mellitus (GDM) is increasing steadily [1]. In addition to adverse maternal outcomes, GDM has been related to adverse fetal outcomes, such as a large for gestational age (LGA) newborn or macrosomia $[2,3]$. Offspring born to mothers with GDM have a higher likelihood of developing obesity, having impaired glucose tolerance, and developing type 2 diabetes mellitus in childhood or in early adulthood [4]. Management of GDM was reported to reduce the frequency of LGA and macrosomia, but fetal adiposity was not normalized $[5,6]$.

In this article titled, "Fetal abdominal obesity detected at 24 to 28 weeks of gestation persists until delivery despite management of gestational diabetes mellitus," Kim et al. [7] investigated whether management of GDM improves fetal abdominal obesity (FAO) in GDM subjects near term. Fetal abdominal overgrowth ratio and odds ratio for FAO were significantly higher in older and/or obese women with GDM but not in young and nonobese women with GDM compared with normal glucose tolerance (NGT) subjects near term. For fetuses of GDM subjects with FAO at the time of GDM diagnosis, the odds ratio for FAO near term and LGA at birth were 7.87 (95\% confidence interval [CI], 4.38 to 14.15) and 10.96 (95\% CI, 5.58 to 20.53), respectively, compared with fetuses of NGT subjects without FAO at GDM diagnosis. In conclusion, FAO detected at the time of GDM diagnosis persisted until delivery despite treatment. Consequently, early diagnosis and treatment might be necessary to prevent near term FAO in high-risk older and/ or obese women. However, there are several issues to be discussed.

First, the result of this study was consistent with those of previous studies that fetal adiposity was not normalized by treatment of GDM. In addition, since FAO was diagnosed at 24 to 28 weeks of gestation, it is not clear whether diagnosis and treatment of FAO before 24 weeks of gestation would be helpful. Actually, there were no specific treatments of FAO during pregnancy. However, to reduce various risks associated with FAO, lifestyle modification including diet control and regular exercise is needed in women with FAO, especially in those with GDM.

Second, this study showed that FAO detected at 24 to 28 weeks of gestation persists until near term only in older GDM patients ( $\geq 35$ years). This is expected because advanced maternal age is associated with various disorders, including GDM and LGA newborn. Considering the rapid increase in maternal age at delivery in Korea, management of FAO is important. Although we do not know why FAO at the time of GDM diagnosis in young patients was not associated with near-term FAO, careful management of FAO should be recommended to reduce the risk of adverse maternal and fetal outcomes, even in young GDM patients.
Corresponding author: Kyung-Soo Kim (iD https://orcid.org/0000-0002-7738-2284 Department of Internal Medicine, CHA Bundang Medical Center, CHA University School of Medicine, 59 Yatap-ro, Bundang-gu, Seongnam 13496, Korea E-mail: kks982@hanmail.net
This is an Open Access article distributed under the terms of the Creative Commons Attribution Non-Commercial License (https://creativecommons.org/licenses/by-nc/4.0/) which permits unrestricted non-commercial use, distribution, and reproduction in any medium, provided the original work is properly cited. 
Finally, a limitation of this study is that various factors affecting fetal growth were not evaluated. Although few studies have evaluated the associations between FAO and various factors, many have investigated risk factors for LGA newborns. The most representative factor is maternal serum lipid measure, such as triglycerides or free fatty acid (FFA). The maternal fasting serum triglycerides level at mid-pregnancy can predict LGA independent of maternal pre-pregnancy body mass index, weight gain during pregnancy, age, and parity in women with GDM [8]. In addition, a high 2 hour-FFA level (but not fasting FFA) at mid-pregnancy is associated with increased risk of LGA newborn in women with GDM [3]. In addition to maternal serum lipids, other known risk factors for delivering LGA newborns include multiparity, gestational weight gain, smoking, and insulin resistance $[9,10]$. Special attention is needed to prevent near-term FAO and LGA newborns in women who have the aforementioned risk factors as well as in older and/or obese women.

\section{CONFLICTS OF INTEREST}

No potential conflict of interest relevant to this article was reported.

\section{REFERENCES}

1. Kim KS, Hong S, Han K, Park CY. The clinical characteristics of gestational diabetes mellitus in Korea: a National Health Information Database Study. Endocrinol Metab (Seoul) 2021;36: 628-36.

2. Kim KS, Park SW, Cho YW, Kim SK. Vitamin D deficiency at mid-pregnancy is associated with a higher risk of postpartum glucose intolerance in women with gestational diabetes mellitus. Endocrinol Metab (Seoul) 2020;35:97-105.

3. Kim SY, Song YS, Kim SK, Cho YW, Kim KS. Postprandial free fatty acids at mid-pregnancy increase the risk of large-for-gestational-age newborns in women with gestational diabetes mellitus. forthcoming 2022.

4. Lowe WL Jr, Scholtens DM, Kuang A, Linder B, Lawrence JM, Lebenthal Y, et al. Hyperglycemia and Adverse Pregnancy Outcome Follow-up Study (HAPO FUS): maternal gestational diabetes mellitus and childhood glucose metabolism. Diabetes Care 2019;42:372-80.

5. Landon MB, Spong CY, Thom E, Carpenter MW, Ramin SM, Casey B, et al. A multicenter, randomized trial of treatment for mild gestational diabetes. N Engl J Med 2009;361:1339-48.

6. Catalano PM, Thomas A, Huston-Presley L, Amini SB. Increased fetal adiposity: a very sensitive marker of abnormal in utero development. Am J Obstet Gynecol 2003;189:1698-704.

7. Kim W, Park SK, Kim YL. Fetal abdominal obesity detected at 24 to 28 weeks of gestation persists until delivery despite management of gestational diabetes mellitus. Diabetes Metab J 2021;45:547-57.

8. Son GH, Kwon JY, Kim YH, Park YW. Maternal serum triglycerides as predictive factors for large-for-gestational age newborns in women with gestational diabetes mellitus. Acta Obstet Gynecol Scand 2010;89:700-4.

9. Kramer MS, Morin I, Yang H, Platt RW, Usher R, McNamara $\mathrm{H}$, et al. Why are babies getting bigger? Temporal trends in fetal growth and its determinants. J Pediatr 2002;141:538-42.

10. Choi SK, Park IY, Shin JC. The effects of pre-pregnancy body mass index and gestational weight gain on perinatal outcomes in Korean women: a retrospective cohort study. Reprod Biol Endocrinol 2011;9:6. 